\title{
SÉANCE DU 25 JUIN 1915
}

Présidence DE M. P.-I. DANGEARD.

M. F. Moreau, vice-secrétaire, donne lecture du procèsverbal de la dernière séance, dont la rédaction est adoptée.

M. le Président annonce à la Société le décès de M. Fernand Guéguen et retrace en quelques mots la carrière scientifique de notre confrère.

\section{DONS FAITS A LA SOCIÉTÉ}

Bär (Johannes), Die Flora des Val Onsernone.

Bennett (Arthur), The Potamogetons of the Philippine Islands.

Briosi (G.), Rassegna crittogamica dell'anno 1913 con notizie sulle Malattie delle Conifere dovute a parasili vegetali.

Briquet (John), La déhiscence des calices capsulaires chez les Capparidacées.

- Sur l'organisılion et les affinités des Capparidacées à fruits vésiculeux.

- Nolice biographique sur les botanistes Édouard et Alfred Huet du Pavillon,

- Thorella, Omhellifère monotype du Sud-Ouest de la France.

Bureau (Éd.), Étude des gîtes minéraux de la France. Bassin de la Basse-Loire.

- Appendice à la Flore fossile de la Basse-Loire.

Büren (Günther von), Die schweizerischen Protomycetaceen (Matériaux pour la flore cryptogamique suisse, $\mathrm{V}, 1$ ).

Camus (Fernand), Sur les Mousses trouvées dans le contenu de l'estomac d'un Mammouth.

Candolle (Casimir de), Engelhardtia Oreamunoa $C . D C$. Une espèce remarquable de Costa-Rica.

Chapoy (Edm.), Le comte Henri de Boissieu.

Dangeard (P.), Le Botaniste. Série XIII, fasc. 4-6.

Fawcett (H.) et Rendle (A.-B.), Flora of Jamaica, III.

T. LXII.

(SÉANCES) 11 
Furrer (Ernst), Vegetations studien in Bormiesischen.

Holmboe (J.), Studies on the vegetation of Cyprus.

Kägi (H.), Die Arten der Sektion Dentaria des Zürcher Oberlandes.

Laurent (J.), L'ancienne végétation forestière de la Champagne pouilleuse.

- Autour du premier Congrès international d'Électroeulture.

- Les Fougères de la Champagne crayeuse.

Lecomte (H.), Notulæ systematicæ.

Lutz (L.), Sur l'accumulation comparée des nilrates dans les plantes parasites et dans leurs supports.

Mattirolo, Sopra 12 avvelenamenti per "Veratrum album " avvenuti per scambio.con " Gentiana lutea " $L$.

- Il Mariscus elatus Vahl, Ciperacea americana reasi spontanea in Piemonte.

- Note sur l'histoire de la "Pierre à Champignons " (Pietra fungaia).

- Tuberaceæ [tripolitanæ].

- Il rimboschimento e la cultura dei lartufi.

Mori (Nello), Sulla natura dei virus filtrabili. Ricerche sperimentali sul Virus Rabico e su di un Ifomicete isolato delle lesioni del Farcino Criptococcico.

Scheuchzer, Herbarium diluvianum, MDCCXXIII.

Seguier, Bibliotheca bolanica, MDCCXL (ces deux ouvrages oflerts par M. l'abbé Hue).

Toni (J.-B. de), La Nuova Nolarisia, Aprile 1915.

Trouard-Riolle (..11/e Y.), Recherches morphologiques et biologiques sur les Radis cultivés.

Walcott (Charles D.), Precambrian Algonkian Algal Flora.

Annales de l'Institut national agronomique, $2^{\mathrm{e}}$ série, XIII, fasc. 1.

Bulletin de la Société française pour l'échange des plantes, $4^{\mathrm{e}}$ fascicule, 1914.

Mémoires de la Société d'Émulation du Doubs, $8^{\mathrm{e}}$ série, VIII, 1913.

M. le Président propose à la Société d'adresser à M. Fischer de Waldheim, à l'occasion de son jubilé scientifique, ses plus chaleureuses et ses plus cordiales félicitations, avec l'expression de sa confiance inébranlable dans le succès des nations alliées qui luttent avec tant d'héroïsme et d'abnégation pour le triomphe de la justice et du droit. La Société adopte la proposition de M. le Président. 
M. le Secrétaire général met à la disposition de la Société des exemplaires d'une circulaire émanant du bureau du Comité des Travaux historiques et scientifiques du Ministère de I'Inslruction publique, relative à une enquête sur les événèments concernant la guerre dans les différentes régions de la France.

M. Emile Perrot prend la parole pour un compte rendu de sa Mission en Afrique.

\title{
L'œuvre botanique et culturale de la Mission de Kisantu (Congo belge);
}

PAR M. ÉmILE PERROT.

\author{
Le JaRdin d'introduction des plantes Utiles \\ et les études botaniques de la Mission de Kisantu.
}

Quelques privilégiés seulement, ont pu jusqu'ici visiter le magnifique Jardin d'introduction que les Pères Jésuites de la Mission du Kwango ont installé à Kisantu, à peu de distance de la voie ferrée qui relie le bassin inférieur du fleuve Congo au Stanley-Pool, près de la station d'Inkissi.

Le signataire de ces lignes ayant fait un séjour de près de deux semaines à Kisantu, en aoùt dernier, c'est un devoir agréable pour lui d'aider à mieux faire connaitre aux botanistes les richesses végétales réunies patiemment dans le vallon judicieusement choisi, où il a passé utilement et agréablement de si belles journées.

Le Jardin d'essai est en effet installé dans une dépression fraìche parcourue par un ruisseau, affluent de l'Inkissi, alimenté par des sources voisines et par les eaux captées pour les services de la Mission. Ces eaux serpentent dans des canaux dont les méandres ont été savamment calculés pour irriguer les diverses parties du jardin ou, tout au moins, pour mettre à portée de la main l'eau indispensable aux arrosages. 


\section{$2 \mathrm{BHL}$ Biodiversity Heritage Library}

1915. "Séance Du 25 Juin 1915." Bulletin de la Société botanique de France 62, 161-163. https://doi.org/10.1080/00378941.1915.10832640.

View This Item Online: https://www.biodiversitylibrary.org/item/8684

DOI: https://doi.org/10.1080/00378941.1915.10832640

Permalink: https://www.biodiversitylibrary.org/partpdf/161112

\section{Holding Institution}

Missouri Botanical Garden, Peter H. Raven Library

\section{Sponsored by}

Missouri Botanical Garden

\section{Copyright \& Reuse}

Copyright Status: Public domain. The BHL considers that this work is no longer under copyright protection.

This document was created from content at the Biodiversity Heritage Library, the world's largest open access digital library for biodiversity literature and archives. Visit BHL at https://www.biodiversitylibrary.org. 